\title{
Efeito da terapia de reposição hormonal sobre o estado férrico
}

\author{
Effect of hormone replacement therapy in iron status
}

\author{
Maria Paula Zanetti Résio 1 \\ Ana Maria de Souza \\ Maria Regina Torqueti Toloi ${ }^{2}$ \\ Zita Maria de Oliveira Gregório ${ }^{3}$ \\ Marlise Bonetti Agostinho Montes ${ }^{3}$ \\ Silvio Antônio Franceschini ${ }^{4}$ \\ Fabíola Attié de Castro 5
}

\begin{tabular}{|c|c|}
\hline & \\
\hline $\begin{array}{l}\text { Ferritina } \\
\text { Estado férrico } \\
\text { Terapia de reposição hormonal } \\
\text { Climatério }\end{array}$ & $\begin{array}{l}\text { Introdução: Na literatura, numerosas publicações relatam a determinação do estado férrico } \\
\text { em crianças, adolescentes e mulheres em fase reprodutiva, no entanto são raras as pesquisas } \\
\text { quanto às alterações do ferro em estoque e eritrograma pós-terapia de reposição hormonal } \\
\text { (TRH) em pré-menopausadas e menopausadas. O aumento dos estoques de ferro em } \\
\text { mulheres pré-menopausadas e menopausadas pode conduzir à elevação do estresse oxidativo } \\
\text { e, conseqüentemente, ao risco de desenvolvimento de câncer e doenças cardiovasculares. } \\
\text { Objetivo: Avaliar o efeito da TRH sobre o eritrograma e o estado férrico em mulheres na pré- } \\
\text { menopausa e na menopausa. Métodos: Foram determinados os eritrogramas e as dosagens } \\
\text { de ferro, capacidade total de ligação do ferro a transferrina (CTLF) e ferritina séricas em } 30 \\
\text { mulheres no climatério antes e após seis meses de TRH com medroxiprogesterona e estradiol. } \\
\text { Os eritrogramas, as dosagens de ferro e CTLF foram determinados por meio da utilização de } \\
\text { métodos clássicos, e a ferritina, por quimiluminescência. Resultados: Após o uso da TRH, } \\
\text { constataram-se significante redução do número de eritrócitos, elevação dos índices } \\
\text { hematimétricos e tendência à diminuição nos níveis de ferro sérico e CTLF. Nenhuma } \\
\text { alteração significante nos níveis de ferritina e no índice de saturação de transferrina foi } \\
\text { detectada após a TRH. Discussão e conclusão: No presente estudo não foram encontradas } \\
\text { alterações nos parâmetros hematimétricos e no estado férrico que impeçam a utilização da } \\
\text { TRH no climatério e na menopausa. Os resultados sugerem que a TRH exerceu efeito } \\
\text { benéfico sobre o estado férrico nas mulheres no climatério deste estudo, mantendo os } \\
\text { estoques de ferro normais e promovendo a elevação dos índices hematimétricos. }\end{array}$ \\
\hline
\end{tabular}

abstract

Background: In literature there are many studies about iron status in children, adolescents and fertile women, but investigations of iron stores and erythrocyte parameters variation after hormone replacement therapy (HRT) are rare. Elevated iron stores, oxidative stress, and estrogen deficiency may place premenopausal and menopausal women in a risk of developing heart disease and cancer. Objective: To evaluate the effect of HRT in erythrogram and iron status in premenopausal and menopausal women. Methods: Hematological indices and iron status were assessed by erythrogram, serum ferritin, iron and transferrin iron-binding capacity (TIBC) in 30 pre- and menopausal women before and after HRT with medroxiprogesterone and estradiol. The blood exam, serum iron and iron-binding capacity were determined by laboratory classic methods, while ferritin was measured by quimiluminescent assay. Results: HRT use was followed by a significant reduction in the absolute number of erythrocyte, an increase of hematimetric indexes and a trend towards a reduction of serum iron levels and TIBC. No alterations on serum ferritin and transferrin saturation index were detected after HRT. Discussion and conclusion: In the present study, alterations in red cell and iron parameters, which could impair the use of HRT in premenopausal and menopausal women, were not observed. Our results suggest that HRT in premenopausal women are beneficial to iron status, maintaining normal iron stores and promoting elevation of red cells indexes.

\section{key words}

Ferritin

Iron status

Hormone replacement

therapy

Premenopausal
1. Mestranda da Faculdade de Ciências Farmacêuticas de Ribeirão Preto da Universidade de São Paulo (FCFRP/USP).

2. Professoras associadas do Departamento de Análises

Clínicas Toxicológicas e Bromatológicas da FCFRP/USP 3. Biomédicas do Departamento de Análises Clínicas Toxicológicas e Bromatológicas FCFRP/USP. 4. Médico ginecologista do Sistema Integrado de Saúde da USP e professor da

Universidade de Ribeirão Preto. 5. Professora doutora do Departamento de Análises Clínicas, Toxicológicas e Bromatológicas da FCFRP/USP.

Estudo desenvolvido no Laboratório de Hematologia Clínica do

Departamento de Análises Clínicas, Toxicológicas e Bromatológicas da FFCFRP/USP.

Este trabalho foi apresentado na forma de pôster no congresso do Colégio Brasileiro de Hematologia, realizado durante os dias 26 a 30 de maio em Salvador, Bahia, no ano de 2002. 


\section{Introdução}

O ferro é vital para quase todos os organismos vivos, participando de uma larga variedade de processos metabólicos, incluindo transporte de oxigênio pela hemoglobina, síntese de DNA, transferência de elétrons $(2,5$, $10)$ e como co-fator de enzimas $(1,17)$.

O ferro ingerido é absorvido pelo intestino e distribuído para os diversos compartimentos férreos do corpo, sendo eles: compartimentos de transporte, de armazenamento e de síntese $(1,2)$. O suprimento e o estoque de ferro são regulados por três proteínas principais: transferrina, receptor de transferrina e ferritina (3).

A transferrina é uma glicoproteína de transporte que carreia o ferro no plasma e no líquido extracelular para suprir as necessidades teciduais, sendo freqüentemente quantificada no laboratório por sua capacidade de ligação da transferrina ao ferro (CTLF), que é a quantidade de ferro total que especificamente pode ser ligada à transferrina $(3,16,17)$.

O receptor de transferrina é uma glicoproteína de membrana, que se liga ao complexo ferro-transferrina, mediando a endocitose do mesmo e resultando na liberação do ferro no meio intracelular $(4,5)$. Recentemente tem sido proposta a utilização da determinação destes receptores de transferrina plasmáticos como parâmetro para detecção de deficiência de ferro, visto que esses receptores encontram-se elevados nesta situação. Os ensaios laboratoriais que quantificam os receptores de transferrina apresentam alta sensibilidade, e os resultados das dosagens apresentam boa correlação com a clínica dos pacientes e com outros parâmetros que determinam o estado férrico, como ferro sérico, CTLF e ferritina (12).

A ferritina é uma macromolécula de peso molecular igual a 560 mil dáltons e formada por uma fração polipeptídica (apoferritina), no interior da qual são encontrados até 4 mil átomos de ferro (13). É a mais importante proteína de reserva do ferro presente em todas as células, especialmente naquelas envolvidas na síntese de compostos que contêm ferro (precursores eritróides) e no metabolismo e reserva do ferro (hepatócitos e macrófagos) (1, $3,5,9$ ). A ferritina pode ser encontrada sob a forma de depósitos intracitoplasmáticos, inclusões lisossômicas ou como aglomerados visíveis ao microscópio (hemossiderina). O ferro da ferritina é facilmente mobilizável quando o organismo dele necessita $(8,12)$. A ferritina circulante reflete diretamente o nível de ferro estocado no organis- mo, sendo um dos parâmetros mais importantes para diagnóstico diferencial da anemia ferropriva, detecção do excesso de ferro e avaliação do estado férrico (12).

O nível normal de ferro no organismo é de difícil determinação, entretanto os extremos, como a anemia por deficiência de ferro ou uma sobrecarga de ferro, são fáceis de serem definidos (16). A prevalência e a gravidade da deficiência de ferro são maiores em mulheres do que em homens devido a diferenças hormonais e exigências relacionadas à reprodução, como menstruação, gravidez e lactação (8). O equilíbrio de ferro nas mulheres em idade reprodutiva e no climatério é sempre precário devido às perdas e sobrecargas fisiológicas deste elemento (11), podendo-se observar como conseqüências destas alterações a anemia microcítica hipocrômica e o aumento do risco do aparecimento de câncer e doenças cardiovasculares, respectivamente (14).

As mulheres no climatério caracterizam-se por apresentar diminuição da produção de estradiol e elevação dos níveis dos hormônios folículo-estimulante e luteinizante. Mulheres nesta fase constituem um grupo populacional altamente sensível às mudanças no estado férrico nutricional e ao estresse oxidativo $(11,14)$. Os sintomas e sinais do climatério são minimizados ou postergados pela implantação da terapia de reposição hormonal (TRH) à base de estradiol e progesterona. A TRH atua normalizando os níveis hormonais femininos, diminui a freqüência de estresse oxidativo celular e conseqüentemente reduz o risco de aparecimento de tumores e doenças cardíacas nas mulheres no climatério e na menopausa (14).

O presente trabalho teve como objetivo avaliar a influência da reposição hormonal sobre o eritrograma e o estado férrico em mulheres no climatério e menopausadas.

\section{Casuística e métodos}

\section{Pacientes}

Foram estudadas 30 mulheres saudáveis no climatério e na menopausa acompanhadas pelo médico ginecologista do Sistema Integrado de Saúde da Universidade de São Paulo/Ribeirão Preto (Sisusp). O diagnóstico de climatério baseou-se em observações clínicas e nas determinações dos níveis séricos dos hormônios estradiol, luteinizante e folículo-estimulante (dados nãoapresentados).

Foram incluídas no estudo mulheres com média de idade de 50,2 anos (variando de 42 a 62 anos) submeti- 
das a TRH por seis meses consecutivos (seis ciclos) e que não faziam uso de quaisquer outros medicamentos. A TRH foi realizada com a ingestão de progesterona $(5 \mathrm{mg}$ de acetato de medroxiprogesterona em comprimido) durante 12 dias consecutivos (dias 17 a 28 do ciclo menstrual) e o uso de gel transdérmico de estradiol $(1 \mathrm{mg}$ de estradiol em $1 \mathrm{~g}$ de gel hidralcoólico) durante todo o ciclo menstrual.

O estudo foi aprovado pelo Comitê de Ética da Faculdade de Ciências Farmacêuticas de Ribeirão Preto da Universidade de São Paulo (FCFRP/USP) e todas as pacientes assinaram termo de consentimento livre e esclarecido concordando em participar do estudo.

\section{Métodos}

\section{Colheita das amostras}

Foram colhidos $15 \mathrm{ml}$ de sangue periférico que foram distribuídos em dois tubos de vidro de 5 e $10 \mathrm{ml}$ contendo EDTA sódico e gel separador, respectivamente (Vacutainer, BD; Vacum II-Labnew, EUA). O sangue anticoagulado foi utilizado para realização do eritrograma, enquanto que 0 soro, obtido após centrifugação do segundo tubo, nas dosagens de ferritina, ferro, capacidade de ligação do ferro à transferrina. As colheitas foram realizadas antes (T0) e seis meses depois (T1) da TRH.

\section{Eritrograma e determinação de estado férrico}

Foram determinados os seguintes parâmetros hematológicos utilizando-se metodologias laboratoriais clássicas: número global de eritrócitos, dosagem de hemoglobina (método da cianometemoglobina, espectrofotômetro digital B 342 II; Micronal, Brasil), microematócrito (centrífuga centimicro; Fanem, Brasil), exame da morfologia eritrocitária em extensão sangüínea corada por Leishman em microscopia ótica (Carl Zeiss, Jena) e cálculos dos índices hematimétricos (volume corpuscular médio, hemoglobina corpuscular média e concentração de hemoglobina corpuscular média).

$\mathrm{O}$ assessoramento do estado férrico incluiu as seguintes determinações: ferro, CTLF, índice de saturação da transferrina e ferritina séricos. Os níveis de ferro sérico e CTLF foram realizados por meio de métodos colorimétricos recomendados pelo Comitê Internacional de Padronização em Hematologia $(6,7)$, utilizando-se os kits Fer-color e Fer-color transferrina, respectivamente (Wiener Lab, Brasil). Todos os testes foram lidos no espectrofotômetro digital B 342 II (Micronal, Brasil). O índice de saturação da transferrina (IST) foi calculado pela fórmula ferro sérico/
CTLF x 100 e expresso em porcentagem. A ferritina sérica foi determinada pelo ensaio imunoenzimático quimioluminescente, com o kit Ferritin Immulite (DPC-Medlab, EUA) e expressa em $\mathrm{ng} / \mathrm{ml}$.

\section{Análise estatística}

Em decorrência de as variáveis analisadas apresentarem uma distribuição gaussiana normal, foram utilizados neste trabalho métodos estatísticos paramétricos. Para analisar os resultados dos parâmetros hematológicos e do estado férrico antes (T0) e depois (T1) da TRH aplicamos o teste pareado paramétrico denominado teste $t$ de Student. Para testar as hipóteses elaboradas em cada caso, utilizaram-se os seguintes valores de referência:

- $p<0,05$ : diferença estatisticamente significante;

- 0,05 $\leq p<0,07$ : tendência a significância;

- $p>0,07$ : diferença não-significante.

Os testes aplicados neste trabalho foram efetuados com o auxílio do programa GraphPad, Software Incorporated, Prism, versão 2.0, 1995.

\section{Resultados}

Os resultados dos parâmetros hematológicos analisados antes (T0) e após seis meses (T1) de terapia de reposição hormonal estão apresentados nas Figuras $\mathbf{1}$ a $\mathbf{6}$. Observaram-se no sangue periférico das mulheres no climatério e menopausadas após a TRH redução do número absoluto de eritrócitos e elevação dos índices hematimétricos. Estas alterações pós-TRH foram estatisticamente significantes $(p<0,05)$.

Em relação à análise do estado férrico (Figuras 7 a 10) verificou-se discreta tendência de redução dos níveis séricos de ferro $(p=0,06)$ e da $\operatorname{CTLF}(p=0,05)$ após a reposição hormonal, porém sem significância estatística. Não foi detectada variação nos níveis de ferritina $(p>0,05)$ e IST $(p>0,05)$ nas pacientes após a TRH. A concentração de hemoglobina e o hematócrito não sofreram alterações significativas pós-TRH $(p>0,05)$.

\section{Discussão e conclusões}

Mulheres no climatério e menopausadas submetidas à terapia de reposição hormonal apresentam equilíbrio férreo positivo, pois as perdas sangüíneas causadas pela menstruação irregular presente na pré-menopausa cessam, a concentração da hemoglobina aumenta e ocorre um acúmulo de ferro no estoque $(11,15)$. 
A literatura relata que os estrógenos são inibidores da eritropoese (17), o que está de acordo com nossos dados quanto à redução estatisticamente significativa no número de eritrócitos circulantes após a reposição hormonal. Contudo, os níveis de hemoglobina aparentemente não

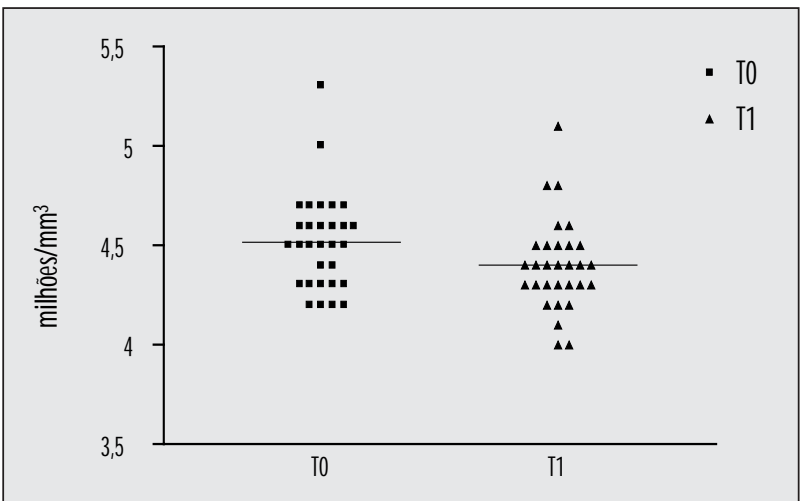

Figura 1 - Distribuição dos valores de eritrócitos das pacientes antes (TO) e após (T1) a terapia de reposição hormonal. Verifica-se redução significativa $(\mathrm{p}<0,05) d a$ contagem absoluta de eritrócitos após o tratamento. A barra horizontal representa a média

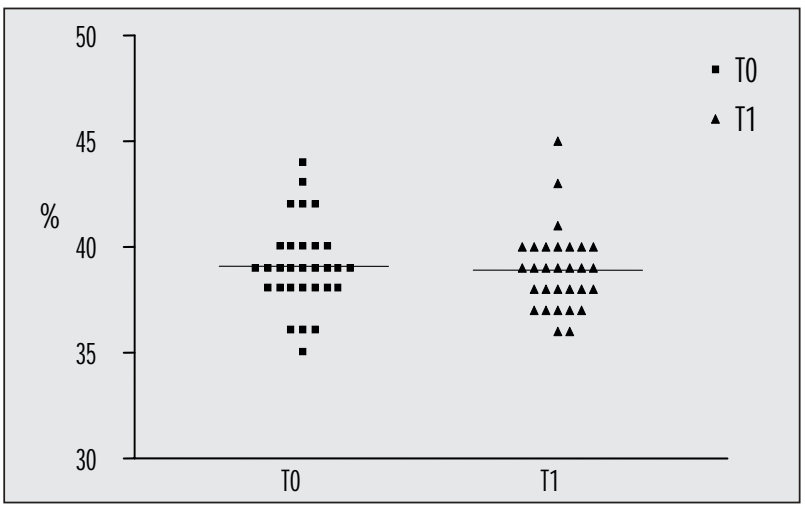

Figura 3 - Distribuição dos valores de hematócrito das pacientes antes (TO) e após (T1) a reposição hormonal. Não houve diferença estatisticamente significativa ( $p>0,05)$ da concentração de hemoglobina antes e após o tratamento. A barra horizontal representa a média

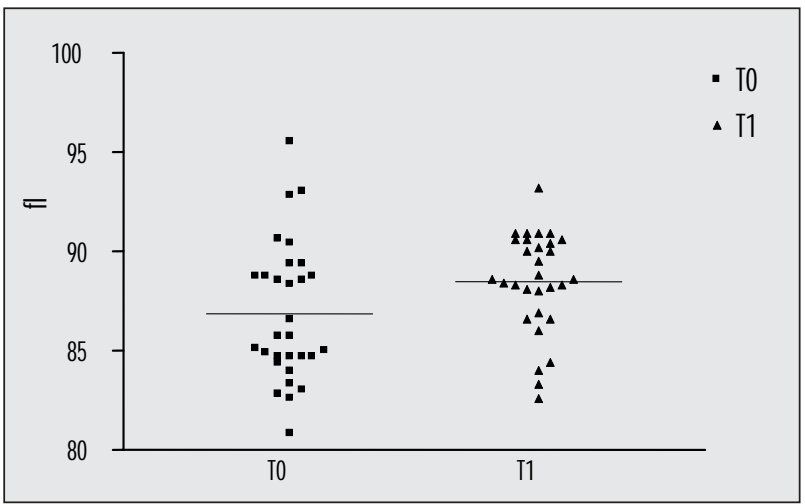

Figura 5 - Distribuição dos valores de VCM das pacientes antes (TO) e após (T1) a reposição hormonal. Observa-se aumento significativo $(\mathrm{p}<0,05)$ do volume corpuscular médio após o tratamento. A barra horizontal representa a média sofreram alterações. Milmann et al. descreveram (11) que mulheres pré-menopausadas e menopausadas apresentam níveis de hemoglobina maiores que aquelas em fase reprodutiva, e que estes níveis pós-terapia de reposição de estrógenos se normalizam. A razão para estas altera-

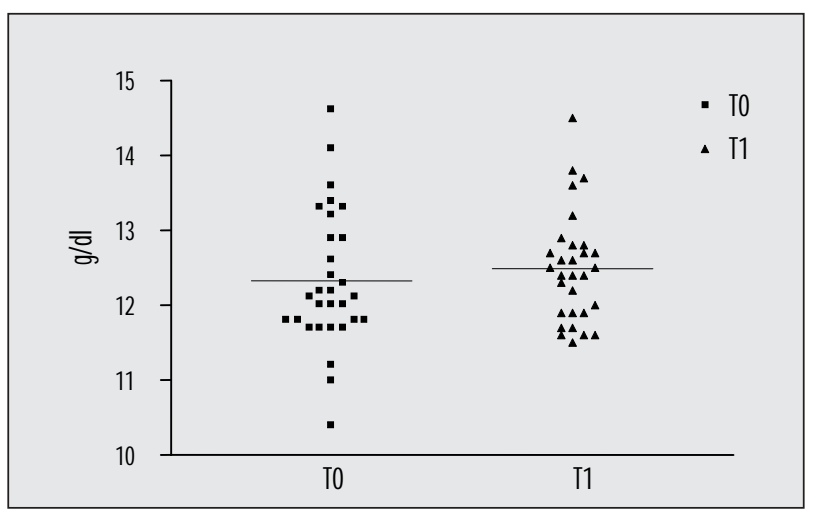

Figura 2 - Distribuição dos valores de hemoglobina das pacientes antes (TO) e após (T1) a reposição hormonal. Não houve diferença estatisticamente significativa $(p>0,05)$ da concentração de hemoglobina antes e após o tratamento. A barra horizontal representa a média

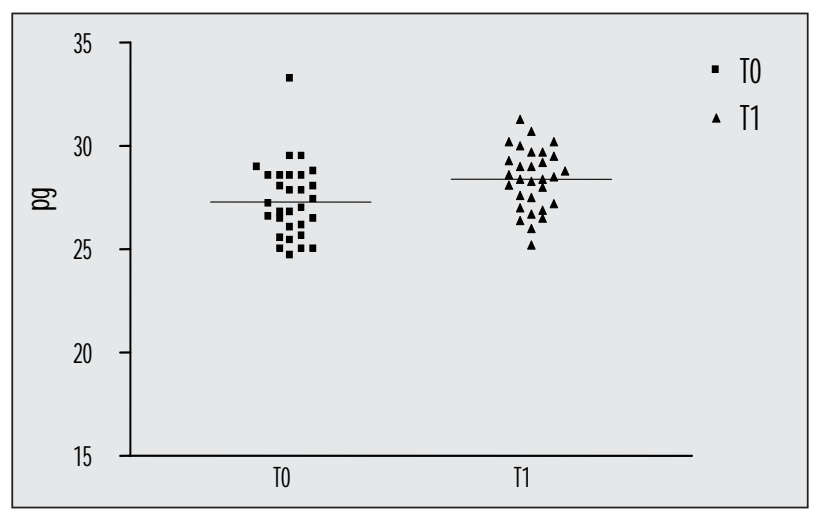

Figura 4 - Distribuição dos valores de HCM das pacientes antes (TO) e após (T1) a reposição hormonal. Observa-se aumento significativo $(\mathrm{p}<0,05)$ da hemoglobina corpuscular média após o tratamento. A barra horizontal representa a média

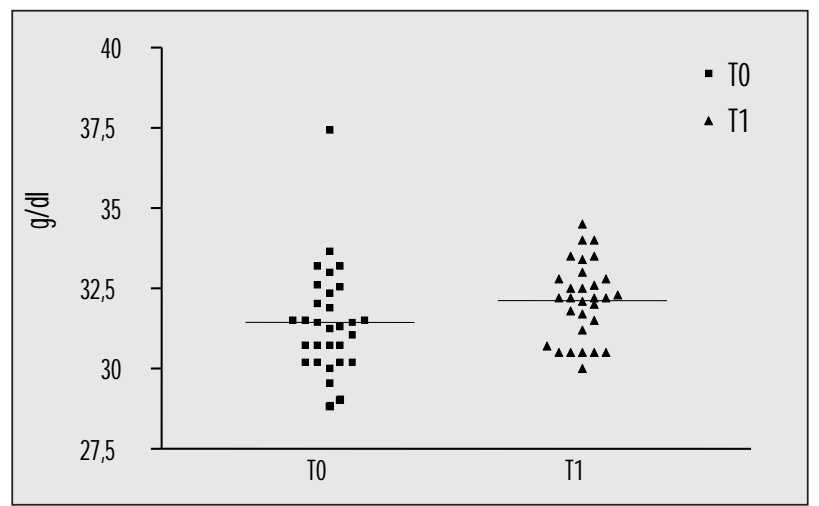

Figura 6 - Distribuição dos valores de CHCM das pacientes antes (TO) e após (T1) a reposição hormonal. Observa-se aumento significativo $(\mathrm{p}<0,05) d a$ concentração de hemoglobina corpuscular média após o tratamento. A barra horizontal representa a média 


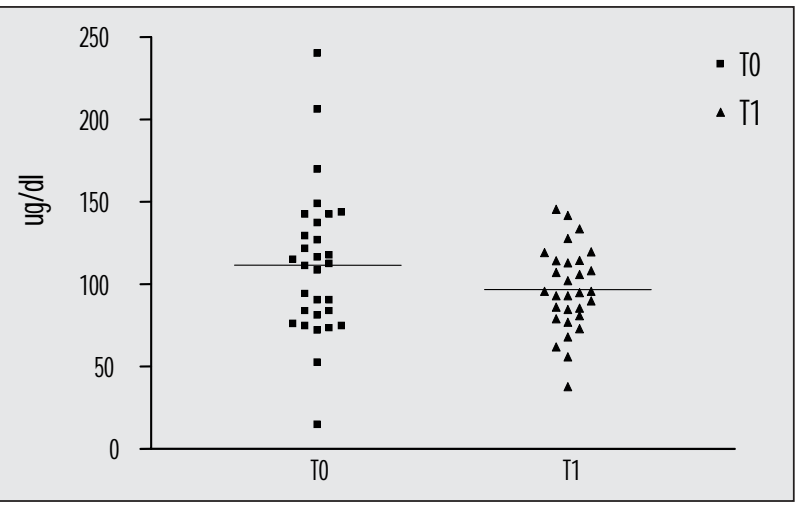

Figura 7 - Distribuição dos valores de ferro sérico das pacientes antes (TO) e após (T1) a reposição hormonal. Verifica-se tendência de redução $(\mathrm{p}=0,06)$ do ferro sérico após o tratamento. A barra horizontal representa a média

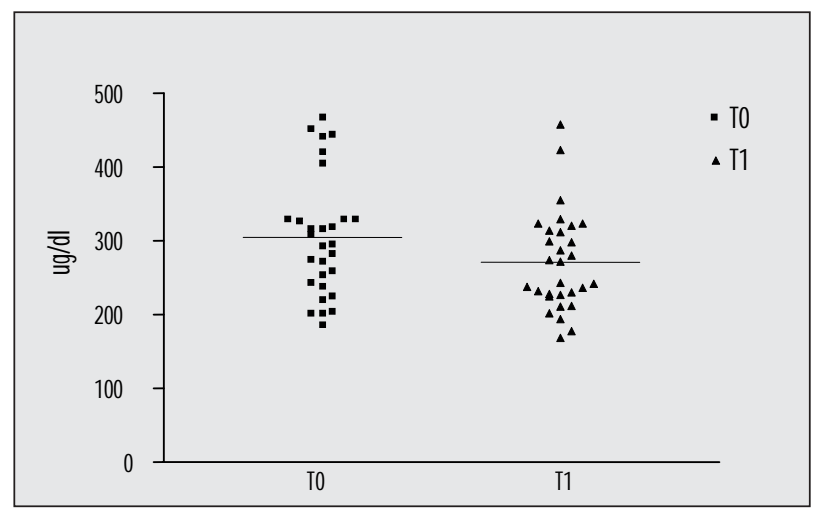

Figura 9 - Distribuição dos valores de CTLF das pacientes antes (TO) e após (T1) a reposição hormonal. Verifica-se tendência de redução $(p=0,05)$ da CTLF sérica após o tratamento. A barra horizontal representa a média

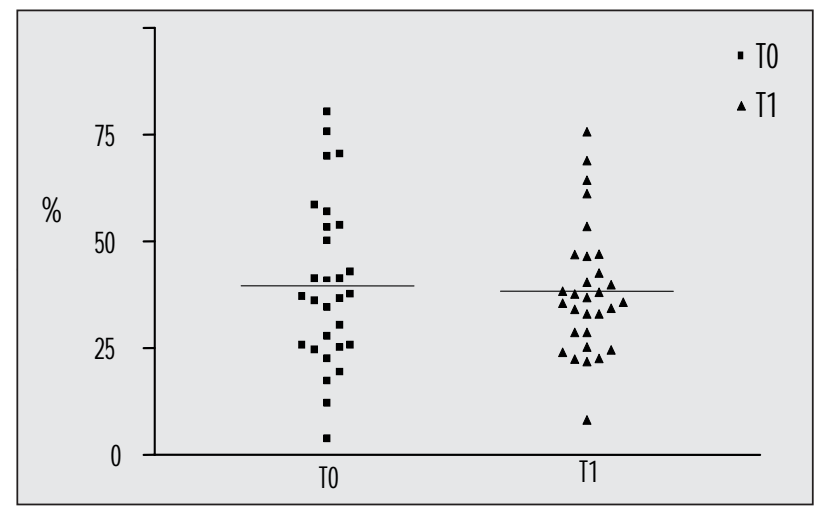

Figura 10 - Distribuição dos valores de IST das pacientes antes (TO) e após (T1) a reposição hormonal. Não houve diferença estatisticamente significativa $(\mathrm{p}>0,05)$ do IST após o tratamento. A barra horizontal representa a média

ções quanto aos níveis de hemoglobina ainda é desconhecida, necessitando-se de mais estudos para uma conclusão mais definitiva. Nossos dados, aqui apresentados, mostram que, em conseqüência da diminuição do número de eritrócitos e da ausência da variação da concentração de hemoglobina, os índices hematimétricos aumentaram significativamente.

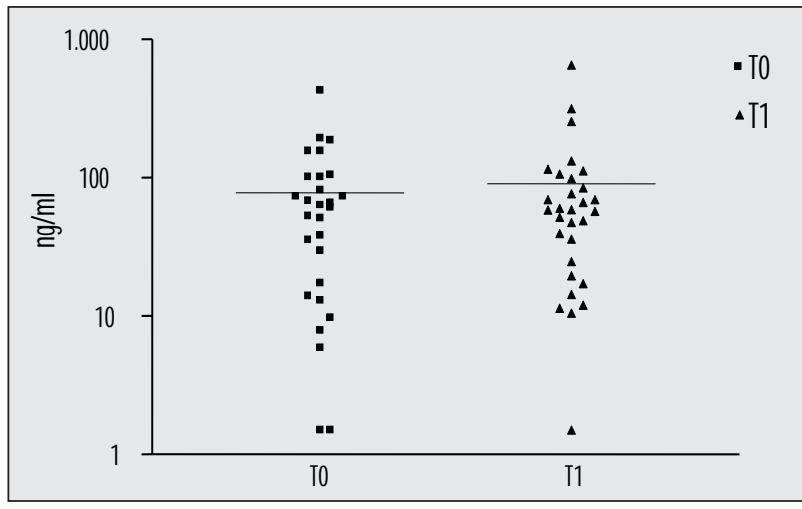

Figura 8 - Distribuição dos valores de ferritina sérica das pacientes antes (TO) e após (T1) a reposição hormonal. Não houve diferença estatisticamente significativa ( $p>0,05)$ da concentração de ferritina sérica após o tratamento. A barra horizontal representa a média

Em relação ao estado férrico, o presente estudo apontou para uma tendência de redução nos níveis séricos de ferro e da CTLF, o que poderia ser esclarecido com a ampliação do número de amostras numa posterior investigação. Por outro lado, sabe-se que a determinação da concentração de ferro sérico sofre grande variação diária, o que impede sua utilização como parâmetro único para avaliação do estado férrico $(2,3)$. Os níveis de ferritina sérica não se alteraram significantemente após seis meses da $T R H$, resultado que indica que a terapia de reposição de estrógenos proposta neste estudo não influenciou na concentração sérica de ferritina, ou seja, na quantidade de ferro estocado.

Em conclusão, no presente trabalho não foram encontradas alterações que impeçam a utilização desta terapia de reposição hormonal no climatério e na menopausa com relação ao balanço de ferro no organismo. Ao contrário, os resultados deste estudo indicam que esta reposição hormonal manteve os estoques de ferro normais. A manutenção do estado férrico em níveis normais pode ser considerada um efeito benéfico desta TRH, uma vez que estoques de ferro normais ou baixos protegem as mulheres menopausadas do estresse oxidativo. Swain et al. (14) relataram ainda que a ausência de estresse oxidativo conduz à diminuição do risco de desenvolvimento de doenças cardíacas e de câncer em mulheres pré-menopausadas e menopausadas.

Tendo em vista a escassez de pesquisas a respeito do tema menopausa e/ou climatério versus estado férrico e o desconhecimento sobre os mecanismos envolvidos na manutenção dos estoques de ferro normais pela TRH, fazse necessária a realização de novas investigações utilizando-se diferentes fontes de estrógenos/progesterona (hormônios sintéticos e naturais) e vias de administração, ampliando-se a casuística e o tempo de tratamento. 


\section{Referências}

1. A isen, P. et al. Iron metabolism. Curr. O pin. Chem. Biol., 3: 200-6, 1999.

2. Cook, J.D. et al. Iron deficiency and the measurement of iron status. Nutr. Res. Rev., 5: 189-202, 1992.

3. Cook,J. The nutritional assessment of iron status. Arch. Latinoam. Nutr., 49: 115-45, 1999.

4. D imitriou, H . et al. So luble transferrin receptor levels and so luble transferrin receptor/log ferritin index in the evaluation of erythropoietic status in childhood infections and malignancy. Acta. Paediatr., 89: 1169-73, 2000.

5. Feelders, R.A. et al. Structure, function and clinical significance of transferrin receptors. Clin. Chem.Lab.M ed., 37:1-10,1999.

6. International Committee for Standardization in Hematology. The measurement of total and unsaturated iron binding capacity in serum. Br. J. Haematol., 38: 281-7, 1978.

7. International Committee for Standardization in Hematology. Recommendations for measurements of serum iron in human blood. Br. J. H aematol., 38: 291-4, 1978.

8. Islam, M.Z. et al. Iron status of premenopausal women in two regions of Bangladesh:prevalence of deficiency in high and low socio-economic gro ups. Eur. J. Clin. N utr., 55: 598-604, 2001.
9. Lafond, J. \& Arnaud, J. Iron Metabolism. Rev. Prat., 50: 945-9, 2000.

10. Lieu, P.T. et al. The roles of iron in health and disease. M ol.Asp. Med., 22: 1-87, 2001.

11. Milman, $\mathrm{N}$. et al. Iron status markers,serum ferritin and hemoglobin in 1,359 D anish women in relation to menstruation, hormonal contraception, parity, and postmenopausal hormone treatment. Ann. Hematol.,65: 96-102, 1992.

12. Paiva,A .A . et al. Parâmetros para avaliação do estado nutricional de ferro. Rev. Saúde Pública, 34: 421-6, 2000.

13. Roy, C .N .\& Enns, C .A.A. Iron homeostasis: new tales from the crypt. Blood, 15: 4020-7, 2000.

14. Swain, J.H . et al. Iron indexes and total antioxidant status in response to soy protein intake in perimenopausal women. Am. J. Clin. Nutr., 76: 165-71, 2002.

15. Vicente, $C$. et al. Method for establishing serum ferritin reference values depending on sex and age. J. Lab. Clin. M ed., 116: 779-84, 1990.

16.W orwo od, M. Regulação do metabolismo do ferro. Anais Nestlé, 52:1-10, 1996.

17. Zago, M.A. et al. Hematologia, fundamentos e prática. São Paulo: Editora A theneu, 2001. 